\title{
Treating the Sex Offender
}

\author{
Benjamin Beit-Hallahmi
}

Clinical Psychologist, Institute for Human Adjustment, University of Michigan

The plight of the convicted sex offender and his chances for treatment are discussed in the light of public opinion and psychiatric knowledge. Popular myths regarding sex offenders are found to be shared by legislators and law enforcement agents. The numerous jurisdictions and legal definitions are cited as major obstacles to effective treatment for sex offenders.

Only three states now have special treatment programs for sex offenders with encouraging results. This is discussed in view of the various treatment methods available. Statistics show that most convicted offenders will be incarcerated without any treatment. The treatment provided for sex offenders reveals an alarming gap between psychological knowledge and correctional practices.

$\mathbf{N}^{\circ}$ o AREA OF Illegal ACTIVities provokes as much mythology, anxiety, and emotion as sex offenses. Public reactions to sex offenses could keep social psychologists and clinicians busy for decades. According to psychoanalysts, these reactions confirm theories regarding unconscious motivation and defense mechanisms. Our aim here is to examine the plight of the convicted offender, keeping in mind that the impact of public reaction is one of the main variables in the situation.

Psychologists and psychiatrists have been reluctant to offer solutions to many social problems. This cautious, scientific conduct is supposed to indicate that "at this stage, we still don't know enough," but it seems that in the case of sex offenders, clearly stating that we don't know would be better than saying nothing. Do we really not know? Although they are unable to agree on a single solution, psychologists and psychiatrists, who are trained to look at facts and to react to more than first impressions, seem to know more about how to treat sex offenders than the people who are actually in charge of the treatment now.

\section{The Legal Situation}

The multiplicity of jurisdictions is responsible for some of the problems involved in treating sex offenders. There are different state and local laws, interpreted differently by judges and prosecuting attorneys, all advocating different ways to treat the sexual offender. Definitions of sexual offenses vary greatly from state to state. Except for a married couple's conventional intercourse, almost every kind of sex activity is defined as a sex offense somewhere. According to Kinsey, if all laws are taken into consideration, most American males are technically sex offenders. ${ }^{1}$

The emotional climate in which sex laws were passed was described by

1. A. C. Kinsey et al., Sexual Behavior in the Human Male (Philadelphia: W. B. Saunders, 1948). 
Karpman as hysterical. ${ }^{2}$ The community demands swift, severe punishment for all sex offenders, even when there is little or no injury to society.

Tappan lists eleven major popular myths regarding sex offenders, which are reflected in legislative action. ${ }^{3}$ These myths may be briefly listed as follows:

1. Tens of thousands of homosexual sex offenders stalk the land.

2. The victims of sex attacks are "ruined for life."

3. Sex offenders are usually recidivists.

4. The minor sex offenders, if unchecked, progress to committing more serious crimes.

5. It is possible to predict the danger of serious crimes by sexual deviance.

6. "Sex psychopathy" or sex deviation is a clinical entity.

7. Sex offenders are lustful and oversexed.

8. Reasonable effective treatment methods to cure deviant sex offenders are known and employed.

9. The sex control laws passed recently are getting at the brutal and vicious sex criminal and should be adopted generally to wipe out sex crime.

10. Civil adjuoication of the sex deviate by indeterminate commitment to a mental hospital is similar to our handling of the insane, and, therefore, human liberties and due process are not involved.

11. The sex problem can be solved merely by passing a new law on it.

2. B. Karpman, The Sexual offender and His Offenses (New York: Julian, 1954).

3. P. Tappan, "Some Myths about the Sex Offender," Federal Probation, June 1955, pp. 7-12.
The terms "sex deviate" and "sex offenders" are used interchangeably, a practice which is completely unjustified in view of the facts. Ellis and Brancale show that not all sex offenders are sexually deviant. ${ }^{4}$ They present the following typology of sex offenders:

A. Normal sex offenders, who are not sexual deviates but commit illegal sex acts.

B. Sexual deviates, who commit illegal sex acts but are sufficiently stable and integrated to maintain their deviation patterns without getting into official difficulties.

C. Psychiatrically deviated offenders, who commit illegal sex acts and are so emotionally disturbed or mentally impaired that they frequently come to official attention.

D. Psychiatrically deviated but sexually nondeviated offenders, who commit illicit sex acts because of general rather than sexual disturbances and are often offcially apprehended.

Since 1938 more than half the states and the District of Columbia have passed so-called "sexual psychopath statutes" allegedly aimed at the protection of society and the rehabilitation of the offender. These laws were often drafted and enacted in haste and in response to public pressure. Generally they have had little benefit; frequently they have caused great harm. The earliest such law, passed in Michigan in 1937, was declared unconstitutional, and others have been attacked by many analysts from the legal and the medical point of view.

From the legal standpoint the "sexual psychopath" is denied due process of law and equal protection of the law because of improper classification. From the psychiatric viewpoint the

4. A. Ellis and R. Brancale, The Psychology of Sex Offenders (Springfield, Ill.: Charles C Thomas, 1956). 
term "psychopath" is too vague and too general to be useful. Hacker and Frym state, "The expression psychopath is not a proper, adequately descriptive, or sufficiently explanatory term, nor is it diagnostically or dynamically acceptable."5

Ellis and Brancale concluded that "legal designation and clarification of sex offenders were found to be quite confused, illogical, and overlapping and to have little relationship to scientific classification of the offender." 8 In 1950 the Group for the Advancement of Psychiatry cautioned against "the use of the term psychopath in the law on several grounds. There is still little agreement on the part of psychiatrists as to the precise meaning of the term. Furthermore, thc term has no dynamic significance."7

\section{Treatment Practices}

Twenty-three states have indeterminate sentence laws that enable judges to sentence sex offenders for "one day to life." This infinite custody period is provided to guarantee intensive treatment and release upon a successful "cure," but in most states treatment facilities are understaffed and little help is available. Sometimes, the result is the release of unrehabilitated offenders and a public outcry.

Only two states, California and Massachusetts, have separate institutions for the study and treatment of sex offenders. The Wisconsin State

5. J. Hacker and M. Frym, "The Sexual Psychopath Act in Practice: A Critical Discussion," California Law Review, vol. 43, 1955, p. 766.

6. Ellis and Brancale, op. cit. supra note 4.

7. Group for the Advancement of Psychiatry, "Psychiatrically Deviated Sex Offenders," 1950.
Prison has a special facility for sex offenders.

The Wisconsin Sex Crimes Law provides that the convicted sex offender be turned over to the state department of public welfare for a complete physical, mental, and social examination before he begins serving his sentence. He is paroled only when the experts are convinced that he can adjust to society.

The special treatment program in Wisconsin claims a success unparalleled by any other correctional system $-a$ recidivism rate of less than 10 per cent for both paroled and probationed offenders. ${ }^{8}$

In California sexually deviant men are treated at the Atascadero State Hospital under the jurisdiction of the state's Department of Mental Hygiene. The sex offenders detained there are known as patients rather than inmates. Research on the outcome of treatment in California shows a success rate similar to Wisconsin's. ${ }^{8}$

\section{Treatment Methods}

\section{The Law Enforcement Approach}

Two textbooks frequently used in law enforcement courses discuss available treatment methods: DeRiver presents the conservative-medical point of view. $\mathrm{He}$ emphasizes the medical, biological, and bizarre aspects of cases, thus reinforcing sensationalism and the public myths regarding sex offenders, and maintains that the only effective treatment is imprisonment. ${ }^{10}$

8. "Wisconsin's Experience with Its Sex Crimes Law, 1951-1958: A Statistical Picture," Wisconsin Department of Public Welfare, Madison, Wis., 1959.

9. L. V. Frisbie, "Studies on Sex Offending in California 1954-1966," California Mental Health Research Digest, vol. 4, 1966, pp. 13541.

10. J. P. DeRiver, Crime and the Sexual 
Reinhardt takes a middle-of-the-road position. He is more open to discussions of psychological and social factors, but the approach is still criminalistic-the police point of view. ${ }^{11}$

These two books seem to reflect the dominant law enforcement attitudes regarding sex offenders: the sex offender is first a criminal and second a dirty, corrupt, evil kind of criminal.

A "treatment" idea that seems to reflect a primitive reaction to sex "perverts" is castration. Guttmacher reported hundreds of cases of castration in this century. ${ }^{12}$ Such treatment is becoming rarer today. Hormonal therapy is a reflection of simplistic, biological notions. It has no effect on behavior. ${ }^{13}$ Most sex offenders are imprisoned without any special treatment.

\section{INSTITUTIONALIZATION and Treatment}

Ellis and Brancale recommend two methods of treatment for psychologically deviated sex offenders: (1) probation, with a provision for psychiatric treatment in the community, or (2) institutionalization, with a provision for psychiatric treatment in the institution. ${ }^{14}$ They maintain that sex offenders do not need special treatment, that other offenders are just as disturbed and inadequate as sex offenders, and that the only sane treatment for criminals is psychiatric treatment. ${ }^{15}$

Psychopath (Springfield, Ill.: Charles C Thomas, 1958) .

11. J. M. Reinhardt, Sex Perversions and Sex Crimes (Springfield, Ill.: Charles C Thomas, 1957).

12. M. S. Guttmacher, Sex Offenses: The Problem, Causes, and Prevention (New York: Norton, 1951).

13. Karpman, op. cit. supra note 2.

14. Ellis and Brancale, op. cit. supra note 4.

15. Ibid.

\section{BehaVior Therapy}

Behavior therapy is increasingly used with sex deviates. ${ }^{16}$ This approach can be classified as symptom-oriented, attacking the specific undesirable behavior in question. Sexual perversions are regarded as learned responses that should be unlearned. ${ }^{17}$

Behavior therapy isolates specific stimuli and changes the existent responses associated with these stimuli. The use of behavior therapy techniques with sexual deviates has been ingenious ${ }^{18}$ and, according to its leaders, the behavior therapy "movement" has had spectacular success-in spite of two major problems emphasized by its opponents and critics: (1) finding specific stimuli and (2) recurrence of symptoms.

Despite the widespread feeling among practitioners that behavior therapy is worth trying, it is rarely, if ever, used with convicted offenders in the United States.

\section{Group Treatment}

Group programs, known as group therapy, group psychotherapy, guided group interaction, etc., are being used with sex offenders. The main question regarding group treatment is whether sex offenders should be segregated in special groups or be merged with other offenders in mixed groups. The answer to this question is related to

16. H. J. Eysenck and S. Rachman, The Causes and Cures of Neurosis (San Diego: Knapp, 1965) ; H. J. Eysenck, Experiments in Behavior Therapy (New York: Macmillan, 1964) .

17. S. Rachman, "Sexual Fetishism: An Experimental Analogue," Psychological Record, vol. 16, 1966, pp. 293-96.

18. A. A. Lazarus, "A Case of Pseudonecrophilia Treated by Behavior Therapy," Journal of Clinical Psychology, vol. 24, 1968, pp. 113-15. 
the basic theoretical approach regarding etiology of sex offenders. Some maintain that all sex offenders have "castration anxiety," as described in psychoanalytic literature; accordingly, a group of sex offenders can direct itself to this common problem. Slater presents another approach that is similar in practice but different in its basic theoretical direction. ${ }^{13}$ In this case, the orientation was interpersonal rather than psychoanalytic, but the group was made up exclusively of sex offenders and there was a great deal of emphasis on symptoms.

A "mixed" person-oriented rather than offense-oriented group is being tried, with offenders of all kinds participating voluntarily. The emphasis is on basic personal problems, self-acceptance, and interpersonal behavior.

\section{Probation}

Canada has a progressive probation program. ${ }^{20}$ Sex offenders who are not considered a threat, such as exhibitionists and pedophiles, are placed on probation and supervised closely. The general recidivism rate is low, as with sex offenders in general. Heterosexual

I9. R. M. Slater, Sex Offenders in Group Therapy (Los Angeles: Sherbourne, 1964).

20. A. K. Gigeroff et al., "Sex Offenders on Probation: The Exhibitionist," Federal Probation, September 1968, pp. 18-21; A. K. Gigeroff et al., "Sex Offenders on Probation: Heterosexual Pedophiles," Federal Probation, December 1968, pp. 17-20. pedophiles show a recidivism rate of between 7 per cent and 13 per cent (depending on age) after the first offense. If there is another offense, the rate jumps to 33 per cent. The highest recidivism rate is among exhibitionists. Gigeroff claims that the incidence of exhibitionistic behavior is partially related to stress in personal life. ${ }^{21}$ Therefore, treatment is generalized and includes help with personal diffculties, together with encouraging feelings of self-worth.

\section{Summary}

No other kind of offender elicits so severe and emotional a public reaction as the sex offender does, and this animus is reflected in the laws. Most of the so-called progressive sexual psychopath laws misuse psychiatric labels to justify punishment without treatment. Only three states-California, Massachusetts, and Wisconsin -have systems that offer treatment rather than punishment, with encouraging results. Several treatment methods are available. It is hard to believe that The Psychology of Sex Offenders, ${ }^{22}$ suggesting a rational approach based on careful research, is still ignored by most correctional systems in the country. It seems that myths and prejudices are still stronger than facts when sexual behavior is involved.

21. Gigeroff, "Sex Offenders on Probation: The Exhibitionist," supra note 20, p. 20.

22. Ellis and Brancale, op. cit. supra note 4. 